BLACK GATHERING 


\section{BLACK GATHERING}

Art,

BLACK OUTDOORS: Innovations in the Poetics of Study A series edited by J. Kameron Carter and Sarah Jane Cervenak 
Ecology, Ungiven Life

SARAH JANE CERVENAK

Duke University Press Durham and London 2021 
(C) 2021 DUKE UNIVERSITY PRESS All rights reserved Printed in the United States of America on acid-free paper $\infty$ Designed by Courtney Leigh Richardson

Typeset in Warnock Pro by Copperline Book Services

Library of Congress Cataloging-in-Publication Data

Names: Cervenak, Sarah Jane, [date] author.

Title: Black gathering : art, ecology, ungiven life /

Sarah Jane Cervenak.

Other titles: Black outdoors.

Description: Durham : Duke University Press, 2021. | Series:

Black outdoors | Includes bibliographical references and index.

Identifiers: LCCN 2020054726 (print)

LCCN 2020054727 (ebook)

ISBN 9781478013556 (hardcover)

ISBN 9781478014478 (paperback)

ISBN 9781478021773 (ebook)

Subjects: LCSH: American literature-2oth century-History and criticism. | American literature-African American authors-History and criticism. | African American art-2oth century. | African American aesthetics. | African American women authors. | African American women artists. | African American artists. | Womanism. | Ecocriticism. Classification: LCC PS153.N5 C39 2021 (print) | LCC PS153.N5 (ebook) | DDC 810.9/89607300904-dc23 LC record available at https://lccn.loc.gov/2020054726 LC ebook record available at https://lccn.loc.gov/2020054727

Cover art: Denver, 2008. ( X) Xaviera Simmons. Courtesy the artist and David Castillo, Miami. 
For Gayl Jones 
This page intentionally left blank 